\title{
Assessment of Ruminal Bacterial Populations and Protozoal Generation Time in Cows Fed Different Methionine Sources ${ }^{1}$
}

\author{
S. K. R. Karnati, ${ }^{\dagger} \dagger$ J. T. Sylvester, ${ }^{*} \dagger^{2}$ S. M. Noftsger, $\dagger^{2}$ Z. Yu, $\dagger$ N. R. St-Pierre, ${ }^{\star} \dagger$ and J. L. Firkins ${ }^{\star} \dagger^{3}$ \\ *Ohio State University Interdisciplinary Nutrition Program (OSUN), and \\ †Department of Animal Sciences, The Ohio State University, Columbus 43210
}

\begin{abstract}
Methionine supplemented as 2-hydroxy-4-(methylthio)-butanoic acid (HMB) has been suggested to alter bacterial or protozoal populations in the rumen. Our objective was to determine if source of Met would change microbial populations in the rumen and to compare those results to samples from the omasum. The ruminal and omasal samples were collected from cows fed control (no Met), DL-Met, HMB, or the isopropyl ester of $\mathrm{HMB}$ (HMBi; estimated $50 \%$ rumen protection) in a replicated $4 \times 4$ Latin square design. In one square, changes in protozoal populations were determined using microscopic counts and denaturing gradient gel electrophoresis (DGGE), whereas changes in bacterial populations were determined using DGGE and ribosomal intergenic spacer length polymorphism (RIS-LP). Neither the protozoal counts nor the DGGE banding patterns derived from protozoa were different among the dietary treatments or for ruminal vs. omasal samples. As revealed by both DGGE and RIS-LP, bacterial populations clustered by treatments in ruminal and especially in omasal samples. Using cows from both Latin squares, the flow of protozoal cells from the rumen was quantified by multiplying protozoal cell count in omasal fluid by the omasal fluid flow (using CoEDTA as a liquid flow marker) or was estimated by rumen pool size of cells multiplied by either the ruminal dilution rate of CoEDTA (after termination of CoEDTA dosing) or the passage rate of Yb-marked particles. Compared with the omasal fluid flow measurement (16.4 h), protozoal generation time was approximated much more closely using the particulate than the fluid passage rate from the rumen (generation times of 15.7 and $7.5 \mathrm{~h}$, respectively). There seems to be minimal selective retention of protozoal genera in the rumen in dairy
\end{abstract}

\footnotetext{
Received June 6, 2006.

Accepted October 10, 2006.

${ }^{1}$ Research was supported by state and federal funds appropriated to the Ohio Agricultural and Development Center, The Ohio State University. Manuscript number 26-06AS.

${ }^{2}$ Current address: Cargill Animal Nutrition Center, Elk River, MN 55360.

${ }^{3}$ Corresponding author: firkins.1@osu.edu
}

cattle fed every $2 \mathrm{~h}$. Data support the validity of the omasal sampling technique under our conditions.

Key words: omasal sampling, denaturing gradient gel electrophoresis, ribosomal intergenic spacer analysis, methionine

\section{INTRODUCTION}

Overfeeding CP leads to excessive excretion of urinary $\mathrm{N}$ into the environment. Balancing the diet for metabolizable amino acids can maintain or even improve milk yield and milk component production while decreasing dietary concentration of CP (Noftsger and St-Pierre, 2003). When 2-hydroxy-4-(methylthio)-butanoic acid (HMB) plus rumen-protected Met was fed to cows in that study, the improvements in milk protein yield were higher than what could be expected by an additional supply of metabolizable Met, suggesting a potential benefit from stimulation of microbial protein synthesis by HMB. The isopropyl ester form of HMB (HMBi) was estimated to have about 50\% ruminal escape (Noftsger et al., 2005) and can therefore be expected to have both ruminal and postruminal effects. The latter authors hypothesized that a ruminal response from degradable HMB would be mediated through protozoa. In a continuous culture experiment in which protozoa were washed out, bacterial $\mathrm{N}$ flow was not affected by source of HMB (Noftsger et al., 2003). In the same study, ribosomal intergenic spacer length polymorphism (RIS-LP), a culture-independent method, was used for determining changes in bacterial populations. The banding patterns tended to group by source of Met, but inoculation source for each period seemed to hide potential banding patterns. From a comprehensive interpretation of these results, we projected that HMB source might alter both bacterial and protozoal populations in vivo.

Recently, Firkins et al. (2006) highlighted how measurements of microbial $\mathrm{N}$ flow might be potentially biased by harvesting a microbial standard from the rumen to represent microbial biomass flowing out of the rumen. Some of the methodological issues include difficulties in obtaining a truly representative single microbial sample from the reticulorumen but also in de- 
termining how samples representing different microbial fractions are quantitatively partitioned to accurately quantify microbial $\mathrm{N}$ flowing from the rumen. Duodenal contents have been the predominant source of digesta to quantify ruminal microbial $\mathrm{N}$ outflow, but in these samples, all protozoa are lysed (Sylvester et al., 2005) and selective lysis of bacteria is also possible (Kennedy et al., 1984). Bacterial marker:N ratios differ for liquid- and solids-associated bacteria, so a weighted average should be used to obtain a standard that represents the total bacteria flowing out of the rumen. However, because of faster passage rate of liquid than particulate matter, the relative contribution of bacterial $\mathrm{N}$ arising from the liquid-associated bacteria should be higher in sites distal from the reticulorumen compared with the rumen (Ahvenjärvi et al., 2000). With the recent improvement of omasal sampling techniques (Noftsger et al., 2005; Firkins et al., 2006), we hypothesized that omasal sampling would allow collection of microbial samples that more accurately represent microbes passing from the rumen.

Although selective retention of isotrichid protozoa in the reticulum or lysis of entodiniomorphid protozoa could bias omasal sampling for protozoa, Firkins and $\mathrm{Yu}$ (2006) concluded that these potential biases probably are less problematic in the lactating dairy cow with very high ruminal passage rates than in prior studies with cattle or sheep fed at much lower DMI as percentages of BW. They also explained why many studies with protozoal count data in the rumen and omasum should not be used to assess protozoal lysis rates or generation times. For example, bypass of drinking water and protozoal chemotaxis for particulate matter should cause protozoal counts in the omasum to be less than corresponding counts in the rumen fluid irrespective of protozoal sequestration in the reticulum or potential autolysis in the omasal fluid. Comparison of ruminal pool size of protozoal cells with omasal flow of protozoal cells, the mathematically correct way to represent protozoal generation time in vivo, has seldom been measured and, to our knowledge, not at all with high-producing dairy cattle (Firkins and $\mathrm{Yu}, 2006$ ).

The use of cultivation-based techniques for enumeration of ruminal bacteria has its own limitations regarding the ability to characterize microbial communities, but these techniques still avoid the important pitfall that an unknown majority of bacteria are currently uncultivable (Firkins and Yu, 2006). Culture-independent techniques targeting the DNA encoding the synthesis of small subunit ribosomal RNA allow direct analysis and quantification of microorganisms. Analysis of RIS-LP has been used for profiling bacterial populations in continuous culture (Noftsger et al., 2003) and to fractionate ruminal bacterial subpopulations (Larue et al., 2005). Recently, denaturing gradient gel electrophoresis (DGGE) has been used to profile predominant bacterial (Larue et al., 2005) and protozoal (Regensbogenova et al., 2004) populations in the rumen and to compare ruminal and duodenal protozoal profiles (Sylvester et al., 2005).

The hypotheses of this experiment were that 1) HMB and HMBi promote changes in ruminal bacterial and protozoal populations, 2) RIS-LP analysis and DGGE allow the detection of changes in ruminal microbial populations resulting from supplementation of a source of Met, and 3) collection of samples from the omasum represents bacteria and protozoa leaving the rumen. The objectives of this study were 1) to compare the effects of Met supplementation on microbial populations in ruminal and omasal samples, 2) to compare RIS-LP and DGGE for the potential to detect changes in the microbial community profiles, and 3) to compare microbial community profiles based on molecular procedures or protozoal counting between the rumen and omasum. Ruminal and omasal samples that were used in this study were used for derivation of data from a companion study (Noftsger et al., 2005).

\section{MATERIALS AND METHODS}

\section{Animals and Experimental Design}

Eight ruminally cannulated Holstein cows were assigned to a replicated $4 \times 4$ Latin square design. For characterization of microbial populations, only one of the squares was analyzed. For outflow and generation time data using total protozoal counts, data from both Latin squares were combined for regression analyses. The dietary treatments were 1) no supplemental methionine (control), 2) HMB at $0.10 \%$ of DM, 3) HMBi at $0.13 \%$ of DM, and 4) DL-Met at $0.088 \%$ of DM. Methionine was supplemented on an equimolar basis across treatments, and the amount of additional Met or Met precursor on a Met basis supplied by each treatment diet was calculated to be $22 \mathrm{~g} / \mathrm{d}$ at $25 \mathrm{~kg} / \mathrm{d}$ of DMI. Treatments were added to a basal diet consisting of $57 \%$ concentrate and $43 \%$ forage, with approximately $70 \%$ of the forage DM from corn silage and $30 \%$ from alfalfa hay (Noftsger et al., 2005). Experimental periods consisted of $28 \mathrm{~d}$, with $\mathrm{d} 1$ through 14 serving to adjust cows to new diets, $d 15$ through $d 20$ to adjust cows to a restricted feeding regimen, and d 21 through d 28 for collection of data. Starting on d 15, cows were restricted to $95 \%$ of their respective average ad libitum DMI determined during the prior $2 \mathrm{wk}$ of adjustment. Using automatic feeders (Ankom Technology, Macedon, NY), cows received approximately one-twelfth of their daily feed allowance every $2 \mathrm{~h}$. Care and handling of the animals was conducted as outlined in the guidelines of The Ohio 
State University Institutional Animal Care and Use Committee.

\section{Collection of Omasal and Ruminal Samples}

Details of sample collection are described elsewhere (Noftsger et al., 2005). Briefly, 500-mL samples were collected from a tube passed through the ruminal cannula and positioned in the omasal canal using a system of alternating vacuum ( $6 \mathrm{~s})$ and positive pressure (4s). On d 22 to 24 of the period, 12 sampling times were set to represent every $2 \mathrm{~h}$ of a complete diurnal cycle. Core samples of ruminal contents from 10 different sites in the rumen were removed at 4 different time points (3 h apart) on d 26, composited, and strained through 2 layers of cheesecloth. All samples to be used for DNA extraction were frozen immediately. Subsamples of composited omasal and ruminal samples were fixed in $50 \%$ formalin (1:1) for microscopic protozoal counts according to standard procedures (Dehority, 1993).

\section{DNA Extraction, RIS-LP, and DGGE Analyses}

Whole omasal contents and ruminal fluid samples were thawed and composited by cow and period. Total community DNA was extracted from 1-mL aliquots of each sample by using the $\mathrm{RBB}+\mathrm{C}$ method (Yu and Morrison, 2004). Methods for bacterial community profiling and cluster analysis using the Bionumerics software (Biosystematica, Devon, UK) were described previously for RIS-LP (Noftsger et al., 2003) and DGGE (Larue et al., 2005). Protozoal community profiling by DGGE analysis was performed as described by Sylvester et al. (2005).

\section{Excision of Bands and DNA Sequencing}

Well-separated intensive bands were carefully excised from the RIS-LP and the DGGE gels for bacteria using razor blades or sterile pipette tips and transferred to microtubes containing $30 \mu \mathrm{L}$ of Tris-EDTA buffer. Following 3 cycles of freezing $\left(-80^{\circ} \mathrm{C}\right.$ for $\left.10 \mathrm{~min}\right)$ and thawing (at $55^{\circ} \mathrm{C}$ for $15 \mathrm{~min}$ ) to facilitate diffusion of the amplicons into the buffer, the amplicons were reamplified by PCR using respective primers and conditions as previously described. The PCR products were purified using a QIAquick PCR purification kit (Qiagen, Valencia, CA) and sequenced at the Plant-Microbe Genomics Facility at The Ohio State University. The DNA sequences were checked for errors by visual evaluation of their respective electropherograms and tested for chimera formation using the Chimera-Check program (Maidak et al., 2001). The sequences were compared with database sequences using BLASTn (Altschul et al., 1997), and the most similar sequences derived from described bacteria were reported. The DNA sequences have been deposited in the GenBank under the accession numbers DQ449424 to DQ449440 and DQ449441 to DQ449470 for bacteria from the rumen and omasum, respectively.

\section{Calculations for Protozoal Generation Time}

Protozoal pool size and generation times were calculated using ruminal and omasal measurements for both of the 2 Latin squares from the companion study (Noftsger et al., 2005). Briefly, rumens were completely emptied on d 27 and 28 at 0800 and 1200 h, respectively, and averaged. The whole contents were separated into fluid and solids by using a grape press used for winemaking. The contents were squeezed until an inconsequential amount of fluid could be further extracted, and the force was kept constant to improve consistency among evacuations. The fluid flow to the omasum was calculated using the Co dosed per day from CoEDTA divided by the average Co concentration of omasal fluid samples taken during d 22 to 24. After termination of the daily dosing of CoEDTA- and Yb-marked feed (immersion and rinsing method) for omasal flow measurements, the concentration of these markers was determined at various times on $\mathrm{d} 25$ and 26 . In all cases, monoexponential elimination rates of $\mathrm{Co}(0.143 \pm 0.027 /$ h) and $\mathrm{Yb}(0.068 \pm 0.008 / \mathrm{h})$ were observed, and the firstorder fractional rates of loss were assumed to approximate the fluid and particulate passage rates from the rumen, respectively. These hourly passage rates were multiplied by 24 to convert to fractional passage rates per day. Theoretically, with a single compartment model, if no fluid were absorbed from the omasum, the outflow of ruminal fluid (rumen fluid volume $\times$ fluid dilution rate) would be identical to omasal fluid flow (daily dose of Co/omasal Co concentration). Consequently, the ruminal fluid outflow was compared with omasal fluid flow using residuals analysis, with the assumption that the observed value was omasal fluid flow and the predicted value was ruminal fluid outflow. Although some protozoa would have been trapped with the particles, we reasoned that protozoa reside largely in this fluid phase that was separated using this system. In the 2 Latin squares, one cow's data were removed for reasons unrelated to treatment (Noftsger et al., 2005). In addition, for the current regressions, one cow had a sampling error for rumen protozoal counts (these data were not in the Latin square design used in Table 1), and another cow had $\mathrm{Co}$ and $\mathrm{Yb}$ passage rates that were 2.7 and 3.6 deviations lower than the respective overall means, resulting in exceptionally and unrealistically low predictions for protozoal outflow compared 
Table 1. Total counts and generic distribution of protozoa ruminal and omasal samples from cows fed different sources of Met ${ }^{1}$

\begin{tabular}{|c|c|c|c|c|c|c|c|c|c|c|}
\hline & \multicolumn{2}{|c|}{ Control } & \multicolumn{2}{|c|}{ НMB } & \multicolumn{2}{|c|}{$\mathrm{HMBi}$} & \multicolumn{2}{|c|}{ DL-Met } & \multicolumn{2}{|c|}{$\mathrm{SE}$} \\
\hline & Rumen & Omasum & Rumen & Omasum & Rumen & Omasum & Rumen & Omasum & Rumen & Omasum \\
\hline $\begin{array}{l}\text { Total, } 10^{6} / \mathrm{mL} \\
\text { Generic distribution, } \%^{2}\end{array}$ & 2.09 & 1.53 & 2.19 & 1.46 & 2.28 & 1.37 & 2.02 & 1.33 & 0.08 & 0.08 \\
\hline Entodinium & 99.1 & 98.2 & 99.0 & 98.1 & 99.0 & 98.0 & 98.7 & 99.2 & 0.2 & 0.4 \\
\hline Diplodiniinae $^{3}$ & 0.1 & 0.5 & 0.2 & 0.1 & 0.3 & 0.1 & 0.4 & 0.1 & 0.1 & 0.1 \\
\hline Isotrichidae $^{4}$ & 0.5 & 1.3 & 0.8 & 1.8 & 0.6 & 1.6 & 0.9 & 0.7 & 0.2 & 0.4 \\
\hline
\end{tabular}

${ }^{1} \mathrm{HMB}=2$-Hydroxy-4-(methylthio) butanoic acid; HMBi = isopropyl ester of HMB. There were no treatment differences $(P>0.10)$.

${ }^{2}$ Percent of total counts; Ophryoscolex, Epidinium, and other genera were periodically detected but not listed.

${ }^{3}$ Subfamily, containing the genera Diplodinium, Eudiplodinium, Ostracodinium, Metadinium, Enoploplastron, and Polyplastron.

${ }^{4}$ Family, containing the genera Isotricha and Dasytricha.

with omasal flows. Therefore, the regressions had $\mathrm{n}=$ 29. For an unbiased assessment of the prediction, the residuals ( $\mathrm{Y}$ axis) should be plotted against the predicted value, rather than the observed value, on the $\mathrm{X}$ axis (St-Pierre, 2003). Moreover, for assessment of mean bias, the predicted value on the $\mathrm{X}$ axis should be centered to its overall mean. That is, the mean of all predictions was subtracted from each individual prediction before regression analyses.

The ruminal pool size of protozoal cells was determined by multiplying the ruminal fluid volume from evacuation measurements by the counts of protozoa in composited ruminal samples. The omasal flow of protozoal cells was determined by multiplying the counts of protozoa in composited omasal fluid by the omasal fluid flow. The generation time of protozoal cells was estimated as the ruminal pool size of protozoal cells divided by the omasal flow of protozoal cells. This generation time is a net value of true generation time adjusted for protozoal cell lysis. As described by Sylvester et al. (2005), generation time can be estimated by multiplying the ruminal pool size of protozoal cells by their expected passage rate from the rumen. In the current study, the protozoal passage rate was estimated by either the fluid dilution or the particulate passage rates from CoEDTAand $\mathrm{Yb}$-marked feed. These protozoal generation times calculated by ruminal outflow measurements (predicted values centralized to the mean of predictions) were compared with those computed using omasal flow (considered the observed values) using residuals analyses.

\section{Statistical Analysis}

Data for generic distribution of protozoa were analyzed as a single $4 \times 4$ Latin square design using SAS Proc Mixed V9.1 (SAS Institute, 2004) according to the following model:

$$
\mathrm{Y}_{\mathrm{ijk}}=\mu+\mathrm{T}_{\mathrm{i}}+\mathrm{P}_{\mathrm{j}}+\mathrm{c}_{\mathrm{k}}+\mathrm{e}_{\mathrm{ijk}}
$$

where $Y_{i j k}=$ the dependent variable, $\mu=$ the overall mean, $\mathrm{T}_{\mathrm{i}}=$ fixed effect of treatment $\mathrm{i}(\mathrm{i}=1$ to 4$), \mathrm{P}_{\mathrm{j}}=$ fixed effect of period $j(j=1$ to 4$), c_{k}=$ random effect of cow $\mathrm{k}(\mathrm{k}=1$ to 4$)$, and $\mathrm{e}_{\mathrm{ijk}}$ is the random residual error, assumed independent and $\sim \mathrm{N}\left(0, \sigma^{2} \mathrm{e}\right)$.

For residuals analyses of protozoal generation time and related data, Proc Reg of SAS was used. Slope bias was assessed by linear regression, and mean bias was assessed both by the intercept of linear regression (StPierre, 2003) or based on a descriptive residuals analysis (Mitchell, 1997).

\section{RESULTS AND DISCUSSION}

\section{Changes in Protozoal Populations}

As expected, ruminal protozoal counts were numerically higher than omasal counts among all the treatment groups. However, neither total protozoal counts nor generic distribution in the ruminal and omasal samples were significantly affected by the supplementation of different methionine sources (Table 1). Similar banding patterns were obtained from the protozoal-specific DGGE analysis, with 5 major bands being obtained from all the samples (Figure 1). In general, the DGGE analysis of both ruminal and omasal protozoal populations agrees with the microscopic analysis. Supplementation of Met sources had no noticeable effect on protozoal banding patterns in samples collected from the rumen or the omasum (data not shown). These results are similar to those of Sylvester et al. (2005), in which protozoal banding patterns were similar between the rumen and duodenum. Taken together, these results suggest a lack of selective retention of certain genera of protozoa, particularly the isotrichids, in the rumen of lactating dairy cattle. However, because DGGE is not quantitative and only detects the predominant populations, further work is needed to verify this finding. Leng et al. (1981) suggested that ruminal sampling might not represent the isotrichid populations because 
Con HMBi HMB DL-Met

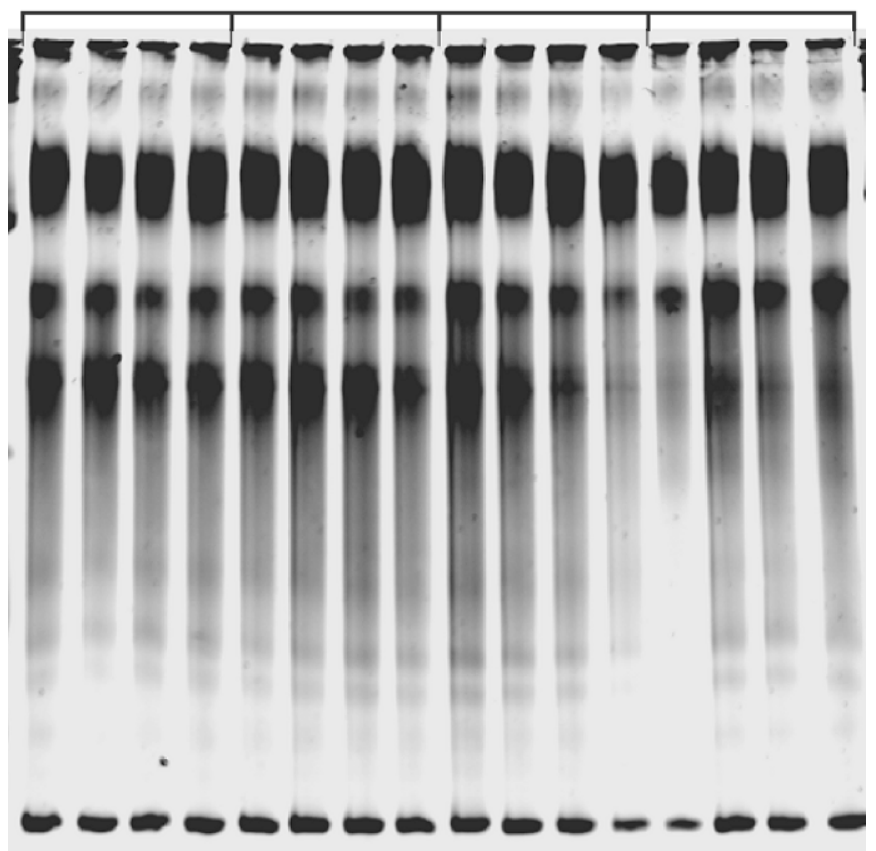

Figure 1. Denaturing gradient gel electrophoresis profile of protozoal populations in ruminal fluid of cows fed different sources of Met. The PCR products were resolved on an $8 \%$ polyacrylamide gel with a 30 to $36 \%$ denaturing gradient. Con = control (no Met); HMB = 2hydroxy-4-(methylthio)-butanoic acid, HMBi = the isopropanol ester of HMB.

of their diurnal migration pattern and sequestration, so ruminal counts might not represent the protozoal populations leaving the rumen. In contrast, continuous feeding (12 times a day) of the diets probably triggered chemotactic migration of isotrichid protozoa from the reticulum toward the soluble sugars in the diet, thus increasing their chances of passing out of the rumen (Sniffen and Robinson, 1987) and probably promoting multiple, attenuated isotrichid counts vs. time curves between each feedings (Abe et al., 1981; Dehority, 2003), greatly reducing the potential error in ruminal counting of isotrichids in the current study.

\section{DGGE Analysis of Bacterial Populations}

Numerous bands were resolved on the DGGE gels from the PCR product from each sample (Figure 2). Although ruminal samples tended to group according to Met source (panel a), the clustering by treatment was even more consistent for the omasal samples (panel b). The bottom lane (cow 879, period 4) probably is due to a bad ruminal sample because protozoa counts also were considered outliers and excluded from regressions from that sampling (see previous discussion). Aside from that observation, more consistent grouping for the omasal sampling also is likely a result of sample processing. The omasal community DNA was extracted from whole omasal content, including particles, which contain higher proportions of fibrolytic bacteria (Larue et al., 2005); in contrast, ruminal community DNA was extracted from only rumen liquid (whole contents were inadvertently used for another purpose). Direct sequencing of the bands excised from the DGGE gels from the ruminal fluid samples provided unambiguous sequence data for several bands. When sequence comparisons using BLASTn were limited to described bacteria, these sequences had highest identities primarily with Lactobacillus, Selenomonas, Streptococcus, Oscillospira, and Clostridium. In addition to these bacteria, bands excised from the gels of the omasal samples also provided highest identities with sequences from Pseudobutyrivibrio, Butyrivibrio, Anaerovibrio, and Megasphaera. The greater bacterial diversity in the omasal samples is perhaps a reflection of the presence of more solids-associated bacteria in these samples compared with the ruminal fluid samples.

The predominance of Lactobacillus-like sequences and lack of amplification of sequences associating with fibrolytic bacteria from the whole omasal contents might be related to sampling and differential amplification of DNA from universal primers. Larue et al. (2005) used more stringent methods to recover tightly adherent bacteria such as Ruminococcus spp. and also reported underrepresentation of Fibrobacter succinogenes in clone libraries even from the rumen particulate phase. The DNA templates from some bacteria such as Streptococcus bovis, Selenomonas ruminantium, Anaerovibrio lipolytica, and Prevotella have a low amplification threshold and, hence, probably are amplified more easily than sequences from bacteria such as $F$. succinogenes (Tajima et al., 2001). However, any such PCR bias would be the same for community DNA extracted from both the ruminal and omasal samples and would still allow a valid comparison of the bacterial profiles between the 2 samples.

Although lactobacilli are not considered predominant bacteria in the rumen in normal circumstances, continuous inoculation into the rumen from the corn silage being fed every $2 \mathrm{~h}$ could have increased their prevalence. Even uninoculated corn silage (as was ours; $30 \%$ of the diet) ensiled for $60 \mathrm{~d}$ had about $5 \times 10^{6} \mathrm{cfu} / \mathrm{g}$ of lactic acid bacteria (Nishino et al., 2004), which could further proliferate when silage is exposed to air (i.e., they are facultative anaerobes). Further, because colony-forming units only reflect viable cells, the number of total cells that can be detected by molecular biology techniques would undoubtedly exceed that mentioned 


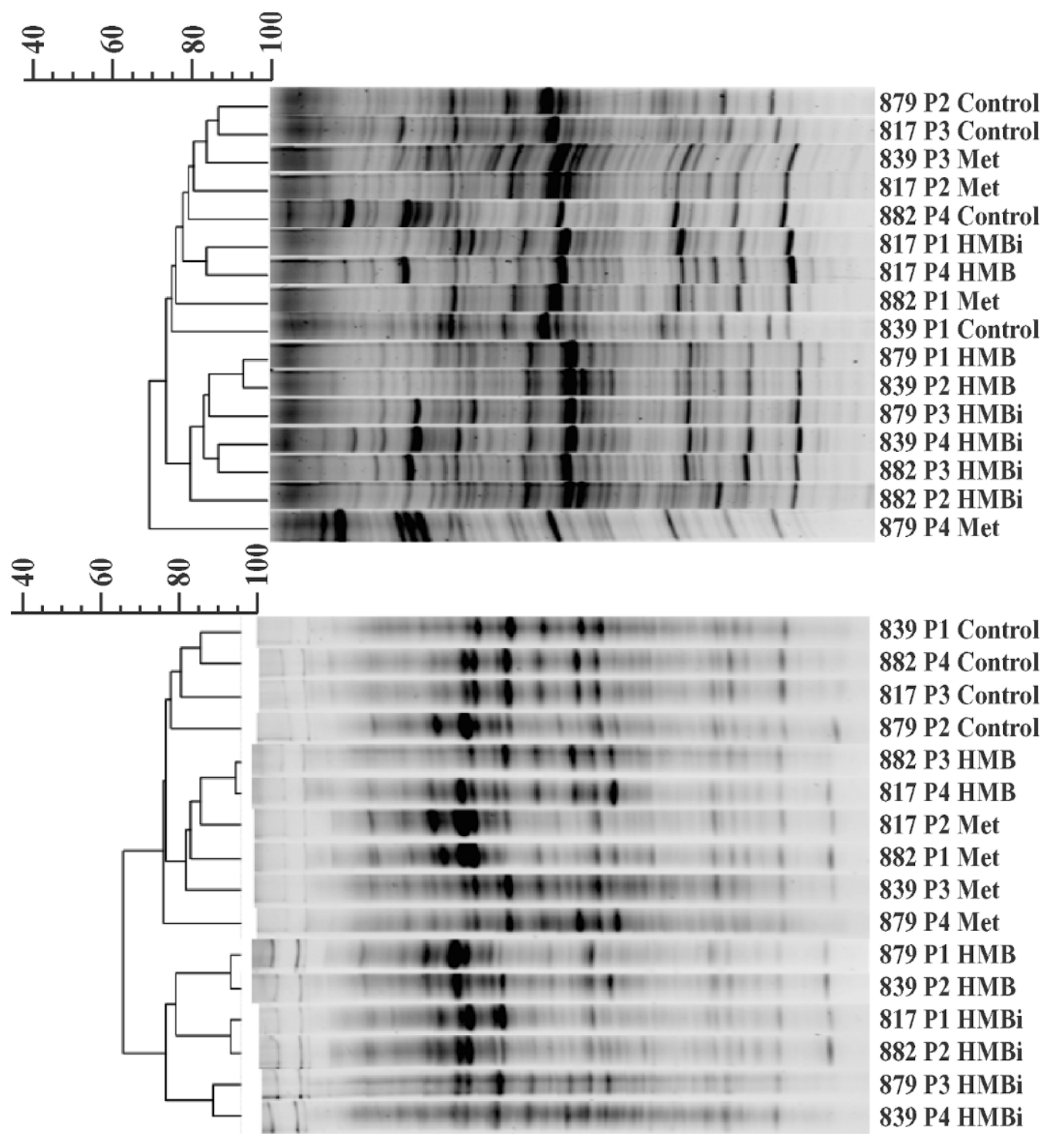

Figure 2. Denaturing gradient gel electrophoresis profiles produced from community DNA samples prepared from (a) ruminal fluid and (b) whole omasal contents. The lanes are labeled with the cow number, period $(\mathrm{P})$, and dietary treatment (control = no Met; HMB = 2hydroxy-4-(methylthio)-butanoic acid, HMBi = the isopropanol ester of HMB, and Met = DL-Met). The calculated similarity coefficients, which were determined using Bionumerics software, are shown on the left hand side of each panel.

above. On the other hand, several of the sequences determined in our study are most closely matched with oleic acid-hydrating lactobacilli (Hudson et al., 2000); all diets had about $12 \%$ cottonseed (which has about $18 \%$ oleic acid on a DM basis). The conversion of oleic acid to trans-C18:1 isomers in continuous culture, even at pH 5.5 (AbuGhazaleh et al., 2005), suggests that the numbers and metabolic activities of lactobacilli and other amylolytic bacteria might increase with increasing ruminal starch availability and decreasing $\mathrm{pH}$. The average $\mathrm{pH}$ reported in the companion study was 5.94 (Noftsger et al., 2005). Therefore, the predominance of bands identifying most closely with lactobacilli could have occurred from a combination of continuous inoculation of lactobacilli that developed a niche in these cows fed unsaturated fat and with a relatively low ruminal $\mathrm{pH}$.

\section{RIS-LP Analysis of Bacterial Populations}

Distinct RIS-LP banding patterns were obtained from gel electrophoresis of the PCR amplicons from whole omasal samples (Figure 3) and ruminal fluid samples (data not shown). The number of bands resolved on the RIS-LP gels was fewer than that on the DGGE gels (Figure 2), but there were several distinct 


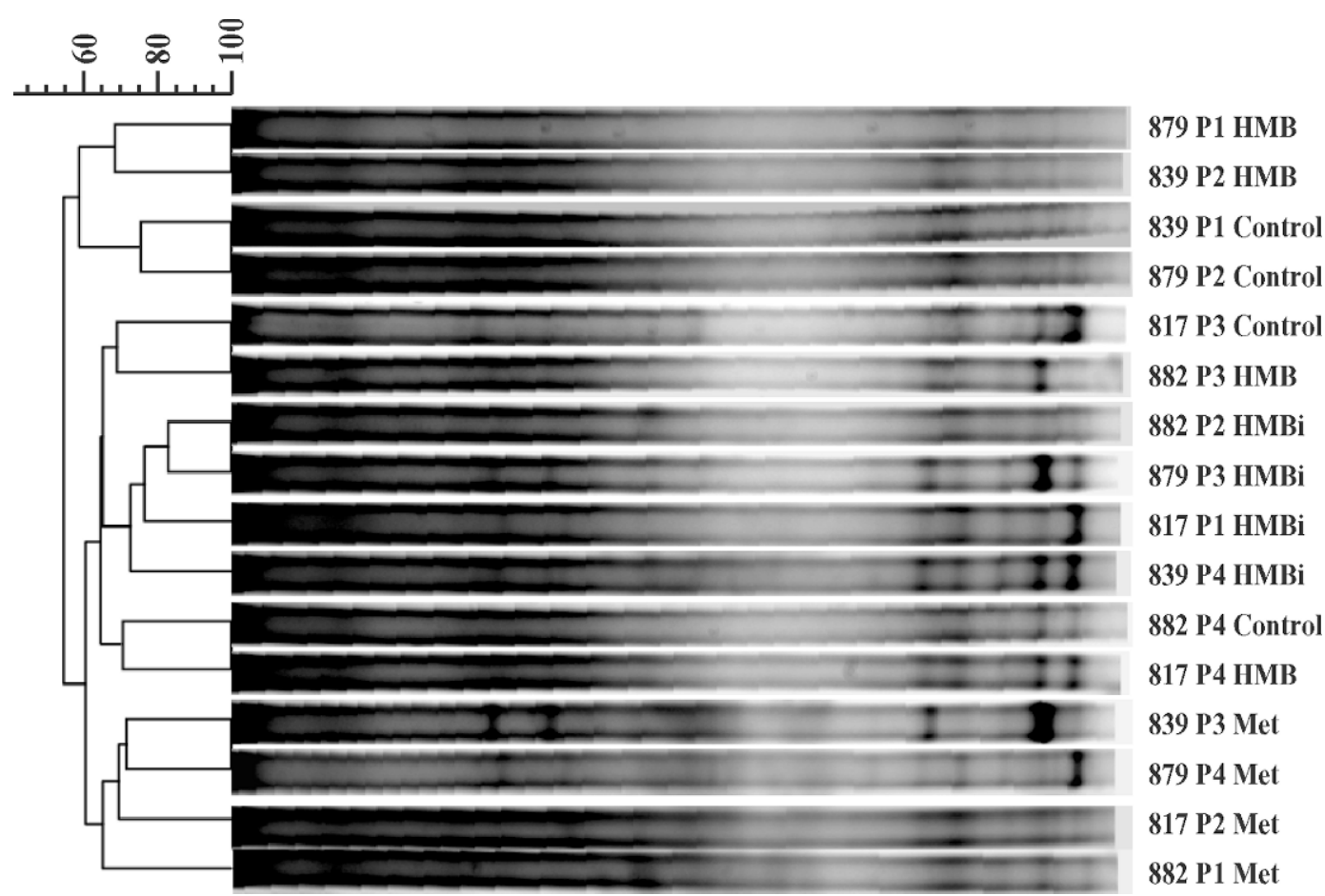

Figure 3. Ribosomal intergenic spacer length polymorphism profiles produced from community DNA samples prepared from whole omasal contents. The calculated similarity coefficients, which were determined using Bionumerics software, are shown on the left hand side of each panel. The lanes are labeled with the cow number, period $(\mathrm{P})$, and dietary treatment (control = no Met; HMB = 2-hydroxy-4-(methylthio)butanoic acid, HMBi = the isopropanol ester of HMB, and Met = DL-Met).

bands in each sample (Figure 3), including 2 to 3 major bands. Cluster analysis of the RIS-LP banding patterns tended to group the samples within each treatment together for both the ruminal and the omasal samples. Elution of the PCR amplicons from the excised bands by the freeze-thaw procedure was less effective with the RIS-LP gel slices because of the larger size of the PCR product (about 1,500 bp). As such, more PCR cycles (45 cycles) had to be used to reamplify an adequate quantity of template DNA for sequencing. When these DNA sequences were compared with those in GenBank using BLASTn, the results were similar to those obtained from sequences from DGGE gels, again confirming that most sequences identified most closely with lactobacilli than with other genera.

\section{Protozoal Outflow from the Rumen}

Total protozoal counts in the omasum averaged only about $49 \%$ of the ruminal counts (Table 1), which is consistent with other observations (Firkins and Yu, 2006). The isotrichids were 2.7 -fold higher in the omasum than in the rumen. The omasal isotrichids were $68 \%$ of ruminal counts compared with 57,58 , and $36 \%$ for large, medium, and small entodiniomorphids in one study (Punia and Leibholz, 1994). One explanation could be that all of the isotrichids had settled below sampling sites. However, distribution of isotrichids as a percentage of total protozoa in the rumen and omasum from slaughtered cattle (where, theoretically, there is no sampling location bias) was similar (Towne and $\mathrm{Na}$ garaja, 1990). Although isotrichids clearly follow a diurnal variation in counts (Dehority, 2003), the assertion that the slowly growing isotrichids sink to the ventral part of the reticulum and rumen to virtually evade passage (Leng and Nolan, 1984) might be, in part, an artifact of methodologies and assumptions used (Firkins et al., 2007). Sinking below the reticulo-omasal orifice would decrease opportunity for isotrichid outflow, but chemotaxis dorsally toward newly ingested feed could provide some compensatory opportunity for passage. If feeding (or eating) more frequently decreases the time that isotrichids sequester in the ventral reticulum and rumen, there could be more passage than what would be expected based on studies with limited feed intake and infrequent feeding. The counts of both entodiniomorphids and isotrichids increased considerably in ruminal fluid of both dorsal and ventral sites after feeding a mixed forage and grain diet (Martin et al., 1999). Therefore, both the high feed intakes (Sylvester et al., 2005) and bihourly feeding regimens (Abe et al., 1981; Dehority, 2003) probably enhance protozoal passage 
(Sniffen and Robinson, 1987) and reduce this potential sampling bias in the current study. Because of their low abundance and subsequently greater likelihood for discrete data (few counts per counting chamber), though, further experiments need to be repeated using animals with greater numbers of isotrichids than in our study to use this procedure to more fully evaluate their outflow. Researchers should consider taking protozoal samples for counting from evacuated rumen samples to increase the accuracy of the pool size of isotrichids, particularly if animals are not fed at bihourly regimens and these populations sink disproportionately to the ventral areas of the reticulum and rumen.

Calculation of pool size of ruminal protozoal cells (and therefore generation time of protozoa) is very dependent on the method of calculating the ruminal fluid volume in which the protozoa distribute. Bacteria rapidly invade and colonize inside these particles, but we consider it unlikely that these particles would be colonized by protozoa. In a study with differing alfalfa silage:hay ratios and different chopping sizes of the hay, when fluid was extracted by squeezing through 4 layers of cheesecloth (Yang et al., 2002), the extracted fluid relative to the total fluid (total mass minus $55^{\circ} \mathrm{DM}$ weight) was consistently about $46 \%$, which is considerably less than our $63 \%$ ( $\mathrm{SD}=4 \%$; data not shown), providing support that our procedure extracted most of the extraparticulate fluid. However, after removing one outlier (more than 2 SD from the mean), the ruminal fluid volume (as estimated by extraction with the grape press, Y) could be predicted accurately from the fluid volume $(\mathrm{X})$ determined by weight of total contents minus the $55^{\circ} \mathrm{DM}$ weight:

$\mathrm{Y}=0.734( \pm 0.053)(\mathrm{X})-12.5( \pm 7.0) ; \mathrm{n}=28 ; \mathrm{r}^{2}=0.88$

The linear regression coefficient and intercept were $P<0.001$ and $P<0.09$ from zero, respectively. Further polynomial models did not improve fit. Solving for $\mathrm{Y}=$ 0 , the $\mathrm{X}$ intercept is $17.0 \%$. Plant particles are very rapidly hydrated, and hay has even greater water-holding capacity than silages (Wattiaux et al., 1992) or fibrous by-products (Bhatti and Firkins, 1995). Consequently, it would be expected that there is a considerable volume of fluid that penetrates plant particles, and a significant proportion of this would not be expressed by physical extraction, explaining the positive $\mathrm{X}$ intercept. The fluid associated with particles therefore would be somewhere between 12.5 and $26.4 \%$ [ $(1-0.734) \times$ 100], and we consider the slope-derived estimate to be more accurate than the intercept-derived one because the Y intercept only tended to be significant and because of the large gap between the smallest datum point and the $\mathrm{X}$ intercept. Finally, liquid volumes determined by pressing whole contents averaged $83.5 \pm 13.0 \mathrm{~L}$, which compared favorably with the volume estimated using CoEDTA $(82.8 \pm 19.7 \mathrm{~L}$; determined as liters per day of fluid flow/fluid dilution rate, the units of which were converted to the reciprocal of day). Therefore, total liquid volume (total mass minus $55^{\circ} \mathrm{DM}$ ) was assumed to overestimate ruminal fluid volume for determination of protozoal cell pool size, and the volume of liquid extracted using the grape press was considered to be the most appropriate value to represent the true volume in which protozoa would distribute.

Treatments had no effects on passage kinetics of Co or $\mathrm{Yb}$ or on resulting calculations of protozoal pool size or protozoal flow rates from the rumen (data not shown). Averaged across treatments, omasal fluid flow $(278 \mathrm{~L} /$ d) agreed well with ruminal fluid outflow (ruminal fluid volume $\times$ fluid dilution rate; $283 \mathrm{~L} / \mathrm{d}$ ). In contrast, using these latter data for fluid outflow and multiplying by ruminal protozoal count, the estimated outflow of protozoal cells (averaging $38.7 \times 10^{10}$ cells/d) was overestimated 2.2-fold compared with omasal flow of protozoal cells $\left(17.8 \times 10^{10}\right.$ cells $\left./ \mathrm{d}\right)$. When pool size of protozoal cells (averaging $11.8 \times 10^{10}$ cells across treatments) was divided by either ruminal outflow or omasal flow of cells, the generation time was much lower when estimated using ruminal outflow of fluid $(7.5 \mathrm{~h})$ than omasal flow $(16.4 \mathrm{~h})$. Microbes must have a net generation time (corrected for cell lysis) that is shorter than the phase from which they pass from the rumen (Dehority, 2003). The residence time of $\mathrm{Co}$ and $\mathrm{Yb}$ (reciprocals of passage rates) averaged 7.1 and $14.9 \mathrm{~h}$, respectively, so the generation times obtained using omasal fluid flow and $\mathrm{Yb}$ outflow seem to be more consistent with values from the literature (Williams and Coleman, 1992; Dehority, 2003) using more direct methodology and are consistent with the concept that entodiniomorphids feed on starch and fiber in the particulate phase (Dehority, 2003). Although protozoal attachment to fiber has often been described, there is little evidence that entodiniomorphids attach for extended periods long enough to influence their residence time (Dehority, 1998). Therefore, the similar generation time based on omasal fluid flow or Yb outflow seems to reflect chemotaxis of entodiniomorphids for feed particles (Williams and Coleman, 1992) rather than washing out with the fluid phase.

If a known volume of a highly pure protozoal cell preparation is dried, the $\mathrm{DM}$ or $\mathrm{N}$ from the dried protozoal cells could be reconstituted to that known volume and known cell count to estimate protozoal $\mathrm{N}$ flow, as done by Punia and Leibholz (1994) and Sylvester et al. (2005). Consequently, important data could be generated using omasal sampling or perhaps a simpler alternative, such as a marker that estimates outflow rate of protozoa. When CoEDTA passage rate was used to 

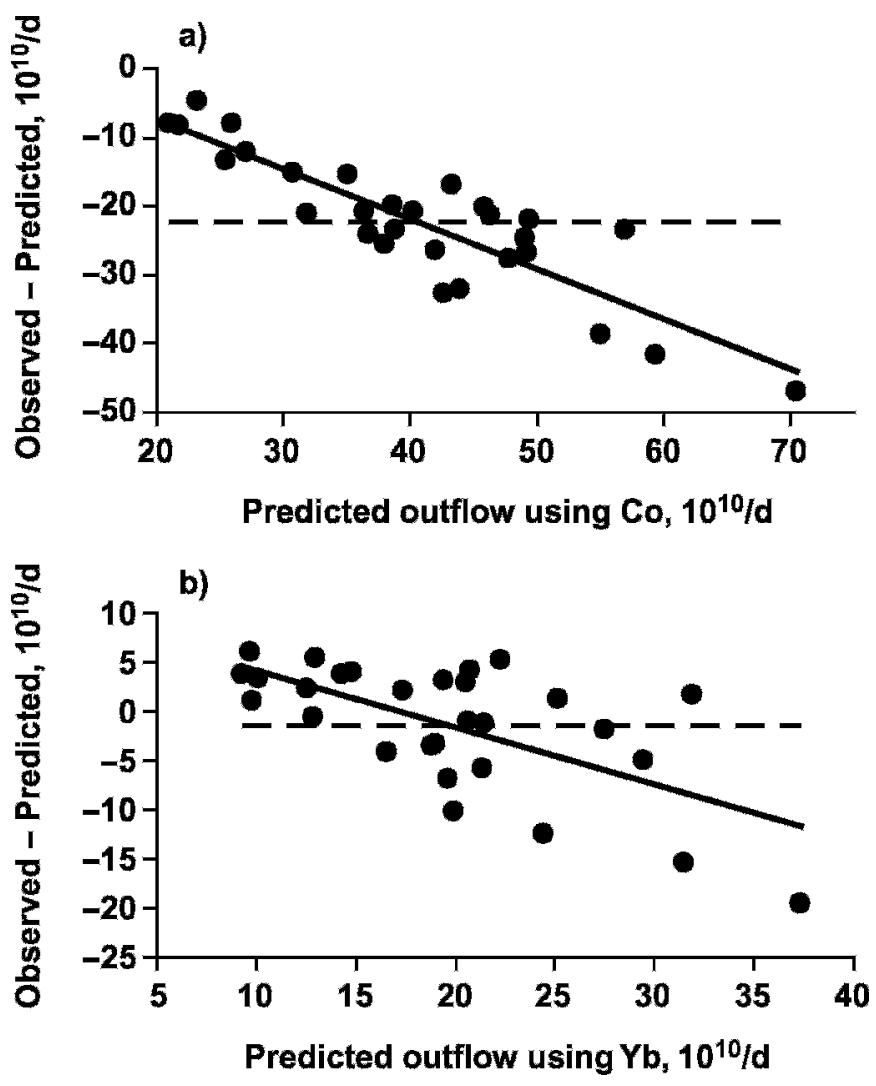

Figure 4. Plots with observed - predicted residuals regressed against predicted values for passage of protozoal cells from the rumen $\left(\times 10^{10} / \mathrm{d}\right)$. Omasal fluid flow $(\mathrm{L} / \mathrm{d})$ multiplied by rumen protozoal counts (cells/L) was assumed to be the observed omasal flow of protozoal cells. For ruminal protozoal pool size, the protozoal cell count in the rumen (cells/L) was multiplied by ruminal fluid volume (L) determined by rumen evacuation. Outflow of protozoal cells from the rumen was predicted by multiplying protozoal pool size by the passage rate (fractional rate per day) of CoEDTA- (panel a) or Yb-marked forage particles (panel b). The dashed line represents the mean deviations (mean bias), which is -22.2 and $-1.44 \times 10^{10}$ cells/d in panels $a$ and $b$, respectively. The solid line represents the regression of the residuals (slope bias). For panel a, $\mathrm{Y}=(22.2( \pm 0.9)-0.731(0.077)(\mathrm{X}-$ $40.4) ; r^{2}=0.77$. For panel b, $\mathrm{Y}=-1.44( \pm 0.94)-0.581( \pm 0.133)(\mathrm{X}-$ $19.7) ; \mathrm{r}^{2}=0.41$. The individual $\mathrm{X}$ values were centered to their respective overall means $\left(40.4\right.$ and $19.7 \times 10^{10}$ cells/d). Intercepts were $P$ $<0.001$ and $P>0.10$ from zero in panels a and b, respectively, and slopes were $P<0.001$ from zero for both regressions.

predict ruminal outflow of protozoal cells relative to omasal flow of protozoal cells (Figure 4a), there was a severe mean bias. None of the residuals was greater than zero, so the CoEDTA outflow calculation consistently overpredicted protozoal cell flow from the rumen. In contrast, when passage rate of $\mathrm{Yb}$-marked forages was used (Figure 4b), the intercept was not different from zero. Also, the residuals were evenly divided with positive and negative values; such a descriptive analysis is an unbiased way to interpret lack of mean bias (Mitchell, 1997). The coefficients for the slopes $(-0.731$ and -0.581 for $\mathrm{Co}$ and $\mathrm{Yb}$ ) were similar to that of the slope $(-0.743)$ of the residuals analysis when CoEDTA was used to predict ruminal fluid outflow relative to omasal fluid flow (data not shown). In the current study, CoEDTA- or Yb-marked particles were dosed 3 times per day for use as omasal flow markers. After the last dose, their concentration was determined over time for passage rate calculations. This approach greatly reduced variation associated with monoexponential fit of the elimination curves compared with our previous experiences in which we have pulse-dosed these markers (Harvatine et al., 2002). Consequently, the consistently high fit for both $\mathrm{Co}$ and $\mathrm{Yb}$ elimination curves argues against marker variation being the cause of this slope bias. Ruminal fluid volume was estimated by rumen evacuation; even with normal error, there should be a distribution of predictions that over- and underestimate the true volume averaged over the entire day. With progressively greater overestimation of ruminal fluid volume, there should be both an increase in the predicted ruminal outflow (a component of the calculations in the $\mathrm{X}$ axis) as well as progressively more negative residuals ( $\mathrm{Y}$ axis) in our analysis; and as evacuation progressively underestimates ruminal fluid volume, there should be a trend of increasingly lower ruminal outflow with increasingly positive residuals. Thus, we have reasoned that the slope bias is, in part, a result of statistical deviations of ruminal fluid volume and the nonrandom effect that this has on $\mathrm{Y}$ and $\mathrm{X}$ calculations. When we plotted these residuals according to treatments (data not shown), there were no consistent patterns.

Based on data using a real-time PCR assay as a protozoal marker (Sylvester et al., 2005), protozoa seemed to flow out of the rumen at rates comparable to or slightly greater than potentially digestible NDF but consistently much slower than that of the ruminal fluid. However, when protozoal $\mathrm{N}$ was expressed as a proportion of the total microbial $\mathrm{N}$, the ratio was similar in the rumen and duodenal digesta. Thus, a passage rate of protozoa comparable with that of the particulate phase in both the current and previous (Sylvester et al., 2005) studies with dairy cattle is faster than that projected by Dijkstra (1994), who modeled passage rate of protozoa to be half that of the particulate passage rate. On the other hand, based on data from ruminants fed at low feed intakes and corroborated with data from studies using the ${ }^{14} \mathrm{C}$-choline technique might underestimate the protozoal passage from high-producing dairy cattle (Firkins et al., 2007).

\section{Protozoal Generation Times in the Rumen}

The net generation time was calculated using omasal fluid (observed values) and predicted using outflow of 

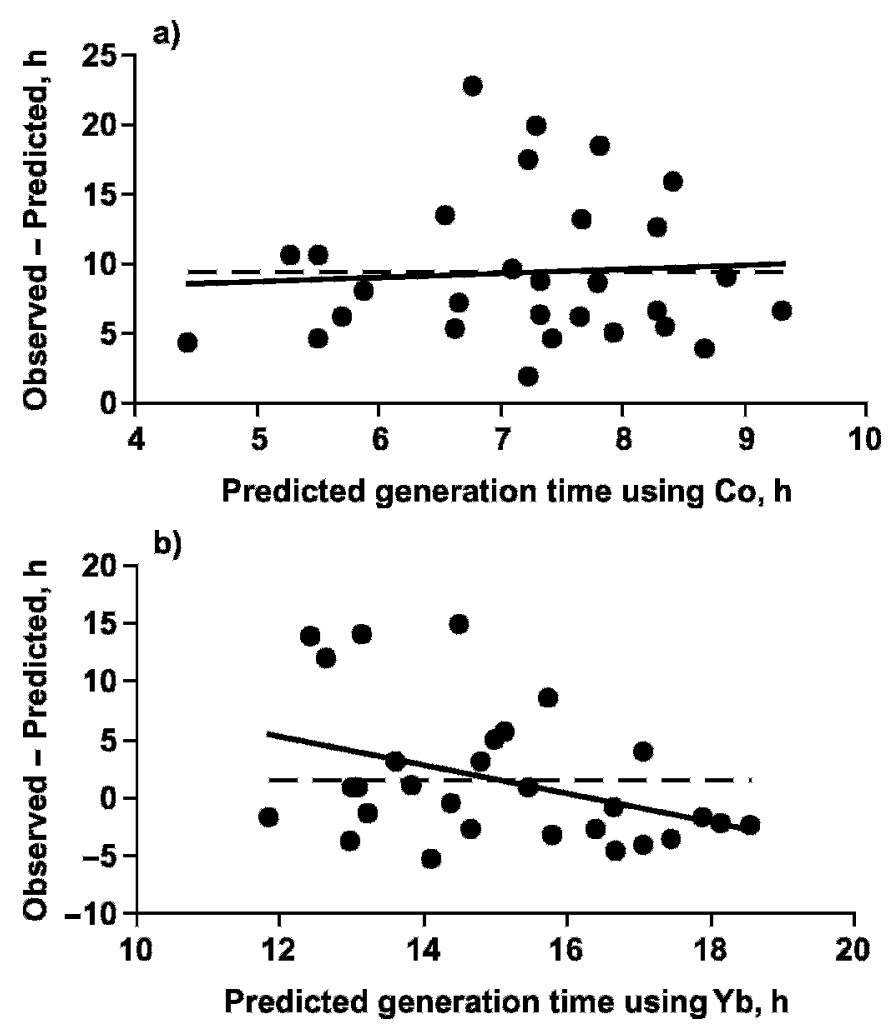

Figure 5. Plots with observed - predicted residuals regressed against predicted values for generation time of protozoal cells from the rumen (h). Ruminal pool size and omasal flow of protozoal cells were calculated as in Figure 4. The observed generation time was ruminal pool size of protozoal cells divided by omasal flow of protozoal cells. For predicted values, outflow of protozoal cells using CoEDTA(panel a) and Yb-marked forage particles (panel b) were used as in calculations from Figures $4 \mathrm{a}$ and $4 \mathrm{~b}$, respectively. The predicted generation time of protozoal cells in the current figure was determined as ruminal pool size of protozoal cells divided by the ruminal outflow of protozoal cells using CoEDTA (panel a) or $\mathrm{Yb}$ (panel b). The dashed line represents the mean deviations (mean bias), which are 9.4 and $1.6 \mathrm{~h}$ in panels a and b, respectively. The solid line represents the slope of the residuals (slope bias). For panel a, Y $=9.4( \pm 1.0)+0.266$ $( \pm 0.864)(\mathrm{X}-7.2) ; \mathrm{r}^{2}=0.01$. For panel b, $\mathrm{Y}=1.6( \pm 1.0)-1.25( \pm 0.56)(\mathrm{X}-$ $15.0) ; r^{2}=0.16$. The individual $\mathrm{X}$ values were centered to their respective overall means $(7.2$ and $15.0 \mathrm{~h})$. The intercept and slope were $P$ $<0.001$ and $P>0.10$ from zero in panel a, and $P>0.14$ and $P=0.03$ from zero in panel b.

protozoal cells derived from passage rates of CoEDTAor Yb-marked forage particles. For the residuals using CoEDTA (Figure $5 \mathrm{a}$ ), but not $\mathrm{Yb}$ (Figure $5 \mathrm{~b}$ ), the intercept was different from zero, documenting mean bias for the Co outflow prediction as in Figure 4a. The slope was not different $(P>0.10)$ from zero for CoEDTA (Figure 5a) and moderately different $(P=0.03)$ from zero for $\mathrm{Yb}$ (Figure $5 \mathrm{~b}$ ). However, in the latter regression, the model explained only $16 \%$ of the variation, and Mitchell (1997) cautioned about using regression approaches to assess model fit, including the likelihood that typical $P$-values used for regression might be overly sensitive (i.e., lower $P$-values should be chosen to discern significance). As discussed for Figure 4, slope bias might be a result of correlation of errors between $\mathrm{Y}$ and $\mathrm{X}$ values both of which rely on measurements for ruminal volume for pool size of protozoal cells. In Figure 5, though, the pool size of protozoa cells is in both the numerator and denominator for predicted values for generation time. Consequently, the degree of over- or underestimation of any single ruminal fluid pool size would largely negate the slope bias associated with this measurement (e.g., overestimation would affect the error in both numerator and denominator similarly, so the error would tend to cancel). There was no detectable pattern when data were identified according to treatment (data not shown). Therefore, the mean generation time for protozoa seems to approximate the mean residence time of $\mathrm{Yb}$ in the rumen.

Researchers have discussed the role of protozoa on $\mathrm{N}$ recycling in the rumen (Hristov and Jouany, 2005; Walker et al., 2005). Dijkstra et al. (1998) have described a sophisticated model depicting protozoal growth and recycling under different dietary conditions. However, much of the information on protozoal growth and lysis known to date and used in that model has been obtained in vitro, and there are few studies corroborating flow of protozoal cells to the omasum or generation times of protozoa in vivo (Firkins and $\mathrm{Yu}$, 2006). The low ruminal $\mathrm{pH}$ seemed to reduce protozoal diversity in our study. However, especially if combined with protozoal harvesting techniques for reconstitution of protozoal cells to a mass basis (Sylvester et al., 2005) and with protozoal community analysis (Regensbogenova et al., 2004), the present work offers considerable potential to advance our knowledge regarding how protozoal ecology affects the efficiency of $\mathrm{N}$ usage under different dietary conditions.

\section{CONCLUSIONS}

Both DGGE and RIS-LP are rapid and reliable methods for analyzing changes in microbial community structure in digesta samples. Direct sequencing of bands from DGGE gels provided good quality sequences, but this approach was more challenging with RIS-LP gels because of the larger size of PCR products. Comparison of the microbial population profiles between the rumen and omasum seem to support our conclusion that omasal samples probably represented the same populations of bacteria and protozoa in the rumen and, because this sampling site is distal to the reticulo-omasal orifice, might better represent those populations passing from the rumen. Particularly for omasal samples, banding profiles consistently grouped by source of supplemental Met, documenting the poten- 
tial to determine population shifts resulting from dietary treatments. Omasal sampling also allowed an apparently more accurate quantification of protozoal flow and generation time than using techniques previously available, although further work is needed with animals harboring larger concentrations of isotrichids and to discern if feeding less frequently than in our study impacts this technique's accuracy. Protozoal outflow and generation time could be approximated using $\mathrm{Yb}$ marked feed, but potential slope bias needs to be considered for future application. The combination of these approaches in future studies should reveal and integrate differences in microbial ecology with differences in nutrient utilization and efficiency of microbial protein synthesis in the rumen.

\section{REFERENCES}

Abe, M., T. Iriki, N. Tobe, and H. Shibui. 1981. Sequestration of holotrich protozoa in the reticulo-rumen of cattle. Appl. Environ. Microbiol. 41:758-765.

AbuGhazaleh, A. A., M. B. Riley, E. E. Thies, and T. C. Jenkins. 2005. Dilution rate and $\mathrm{pH}$ effects on the conversion of oleic acid to trans C18:1 positional isomers in continuous culture. J. Dairy Sci. 88:4334-4341.

Ahvenjärvi, S., A. Vanhatalo, P. Huhtanen, and T. Varvikko. 2000. Determination of reticulo-rumen and whole-stomach digestion in lactating cows by omasal canal or duodenal sampling. Br. J. Nutr. 83:67-77.

Altschul, S. F., T. L. Madden, A. A. Schäffer, J. Zhang, Z. Zhang, W. Miller, and D. J. Lipman. 1997. Gapped BLAST and PSI-BLAST: A new generation of protein database search programs. Nucleic Acids Res. 25:3389-3402.

Bhatti, S. A., and J. L. Firkins. 1995. Kinetics of hydration and functional specific gravity of fibrous feed by-products. J. Anim. Sci. 73:1449-1458.

Dehority, B. A. 2003. Rumen Microbiology. Nottingham University Press, Nottingham, UK.

Dehority, B. A. 1993. Laboratory manual for classification and morphology of rumen ciliate protozoa. CRC Press, Inc., Boca Raton, FL.

Dehority, B. A. 1998. Generation times of Epidinium caudatum and Entodinium caudatum, determined in vitro by transferring at various time intervals. J. Anim. Sci. 76:1189-1196.

Dijkstra, J. 1994. Simulation of the dynamics of protozoa in the rumen. Br. J. Nutr. 72:679-699.

Dijkstra, J., J. France, and S. Tamminga. 1998. Quantification of the recycling of microbial nitrogen in the rumen using a mechanistic model of rumen fermentation processes. J. Agric. Sci. 130:81-94.

Firkins, J. L., A. N. Hristov, M. B. Hall, G. A. Varga, and N. R. StPierre. 2006. Integration of ruminal metabolism in dairy cattle. J. Dairy Sci. 89(E Suppl.):E31-E51.

Firkins, J. L., and Z. Yu. 2006. Characterisation and quantification of the microbial populations in the rumen. Pages 19-54 in Ruminant Physiology, Digestion, Metabolism and Impact of Nutrition on Gene Expression, Immunology and Stress. K. Sejrsen, T. Hvelplund, and M. O. Nielsen, ed. Wageningen Academic Publishers, Wageningen, the Netherlands.

Firkins, J. L., Z. Yu, and M. Morrison. 2007. Ruminal nitrogen metabolism: Perspectives for integration of microbiology and nutrition for dairy. J. Dairy Sci. 90(E Suppl.) (accepted)

Harvatine, D. I., J. E. Winkler, M. Devant-Guille, J. L. Firkins, N. R. St-Pierre, and M. L. Eastridge. 2002. Whole linted cottonseed as a forage substitute: Fiber effectiveness and digestion kinetics. J. Dairy Sci. 85:1988-1999.
Hristov, A. N., and J.-P. Jouany. 2005. Factors affecting the efficiency of nitrogen utilization in the rumen. Pages 117-166 in Nitrogen and Phosphorus Nutrition of Cattle and Environment. A. N. Hristov and E. Pfeffer, ed. CAB International, Wallingford, UK.

Hudson, J. A., Y. Cai, R. J. Corner, B. Morvan, and K. N. Joblin. 2000. Identification and enumeration of oleic acid and linoleic acid hydrating bacteria in the rumen of sheep and cows. J. Appl. Microbiol. 88:286-292.

Kennedy, P. M., G. P. Hazlewood, and L. P. Milligan. 1984. A comparison of methods for the estimation of the proportion of microbial nitrogen in duodenal digesta, and of correction for microbial contamination in nylon bags incubated in the rumen of sheep. Br. J. Nutr. 52:403-417.

Larue, R., Z. Yu, V. A. Parisi, A. R. Egan, and M. Morrison. 2005. Novel microbial diversity adherent to plant biomass in the herbivore gastrointestinal tract, as revealed by ribosomal intergenic spacer analysis and rrs gene sequencing. Environ. Microbiol. 7:530-543.

Leng, R. A., M. Gill, T. J. Kempton, J. B. Rowe, J. V. Nolan, S. J. Stachiw, and R. L. Preston. 1981. Kinetics of large ciliate protozoa in the rumen of cattle given sugar cane diets. Br. J. Nutr. 46:371-384

Leng, R. A., and J. V. Nolan. 1984. Nitrogen metabolism in the rumen. J. Dairy Sci. 67:1072-1089.

Maidak, B. L., J. R. Cole, T. G. Lilburn, C. T. Parker, Jr., P. R. Saxman, R. J. Farris, G. M. Garrity, G. J. Olsen, T. M. Schmidt, and J. M. Tiedje. 2001. The RDP-II (Ribosomal Database Project). Nucleic Acids Res. 29:173-174.

Martin, C., E. Devillard, and B. Michalet-Doreau. 1999. Influence of sampling site on concentrations and carbohydrate-degrading enzyme activities of protozoa and bacteria in the rumen. J. Anim. Sci. 77:979-987.

Mitchell, P. L. 1997. Misuse of regression for empirical validation of models. Agric. Syst. 54:313-326.

Nishino, N., H. Wada, M. Yoshida, and H. Shiota. 2004. Microbial counts, fermentation products, and aerobic stability of whole crop corn and a total mixed ration ensiled with and without inoculation of Lactobacillus casei or Lactobacillus buchneri. J. Dairy Sci. 87:2563-2570.

Noftsger, S., N. R. St-Pierre, and J. T. Sylvester. 2005. Determination of rumen degradability and ruminal effects of three sources of methionine in lactating cows. J. Dairy Sci. 88:223-237.

Noftsger, S. M., and N. R. St-Pierre. 2003. Supplementation of methionine and selection of highly digestible rumen undegradable protein to improve nitrogen efficiency for milk production. J. Dairy Sci. 86:958-969.

Noftsger, S. M., N. R. St-Pierre, S. K. R. Karnati, and J. L. Firkins. 2003. Effects of 2-hydroxy-4-(methylthio) butanoic acid (HMB) on microbial growth in continuous culture. J. Dairy Sci. 86:2629-2636.

Punia, B. S., and J. Leibholz. 1994. Effect of level of intake of kikuyu (Pennisetum clandestinum) grass hay on the flow of protozoal nitrogen to the omasum of cattle. Anim. Feed Sci. Technol. 47:77-87.

Regensbogenova, M., P. Pristas, P. Javorsky, S. Y. Moon-van der Staay, G. W. M. van der Staay, J. H. P. Hackstein, C. J. Newbold, and N. R. McEwan. 2004. Assessment of ciliates in the sheep rumen by DGGE. Lett. Appl. Microbiol. 39:144-147.

SAS Institute. 2004. SAS/STAT 9.1 User's Guide. SAS Institute Inc., Cary, NC.

Sniffen, C. J., and P. H. Robinson. 1987. Microbial growth and flow as influenced by dietary manipulations. J. Dairy Sci. 70:425-441.

St-Pierre, N. R. 2003. Reassessment of biases in predicted nitrogen flows to the duodenum by NRC 2001. J. Dairy Sci. 86:344-350.

Sylvester, J. T., S. K. R. Karnati, Z. Yu, C. J. Newbold, and J. L. Firkins. 2005. Evaluation of a real-time PCR assay for measuring the ruminal pool and duodenal flow of protozoal nitrogen. J. Dairy Sci. 88:2083-2095.

Tajima, K., R. I. Aminov, H. Nagamine, H. Matsui, M. Nakamura, and Y. Benno. 2001. Diet-dependent shifts in the bacterial population of the rumen revealed with real-time PCR. Appl. Environ. Microbiol. 67:2766-2774. 
Towne, G., and T. G. Nagaraja. 1990. Omasal ciliated protozoa in cattle, bison, and sheep. Appl. Environ. Microbiol. 56:409-412.

Walker, N. D., C. J. Newbold, and R. J. Wallace. 2005. Nitrogen metabolism in the rumen. Pages 71-115 in Nitrogen and Phosphorus Nutrition of Cattle. E. Pfeffer and A. Hristov, ed. CABI Publishing, Cambridge, MA.

Wattiaux, M. A., D. R. Mertens, and L. D. Satter. 1992. Kinetics of hydration and effect of liquid uptake on specific gravity of small hay and silage particles. J. Anim. Sci. 70:3597-3606.
Williams, A. G., and G. S. Coleman. 1992. The Rumen Protozoa. Springer-Verlag, New York.

Yang, W. Z., K. A. Beauchemin, and L. M. Rode. 2002. Effects of particle size of alfalfa-based dairy cow diets on site and extent of digestion. J. Dairy Sci. 85:1958-1968.

Yu, Z., and M. Morrison. 2004. Improved extraction of PCR-quality community DNA from digesta and fecal samples. Biotechniques 36:808-812. 